\title{
Increasing the selectivity of the hydrocarbon feedstock pyrolysis
}

\author{
E. Magaril ${ }^{1} \&$ R. Magaril ${ }^{2}$ \\ ${ }^{1}$ Ural Federal University, Russia \\ ${ }^{2}$ Tyumen State Oil and Gas University, Russia
}

\begin{abstract}
The process of hydrocarbon feedstock pyrolysis is the principal method used to produce ethylene which is a primary product utilized in the fabrication of plastic materials, synthetic resins, fibers and other similar products. The current level of process capacity and the necessity to steadily increase the petrochemical industry's potential make the problem of improving the efficiency of the process an urgent one.

The aim of the present work in terms of the pyrolysis mechanism analysis is to develop a method of increasing the pyrolysis selectivity for ethylene with minimal hydrogen consumption.

It was shown on the base of established relative reactivity of different type $\mathrm{C}-\mathrm{H}$ bonds in the reactions of interaction with $\mathrm{H}$ atoms and $\mathrm{CH}_{3}$ radicals, that the selectivity of the hydrogen atoms and methyl radicals in the substitution reactions at high temperatures are notably different. This makes possible a new method of controlling the selectivity of ethylene formation based solely on the influence of the concentration ratio of the chain carrier radicals $[\mathrm{H}]:\left[\mathrm{CH}_{3}\right]$ in the reaction mixture on the reaction output irrespective of changes in temperature, pressure and contact time. The minimum amount of hydrogen required to produce the desired effect was estimated.

Keywords: pyrolysis, homogeneous catalysis, process selectivity, ethylene.
\end{abstract}

\section{Introduction}

Production of ethylene by the pyrolysis of hydrocarbons in 2013 accounted for more than 140 million tons. With such large scale ethylene production even a 
slight improvement in the process technology, aimed at improving the selectivity for ethylene, has a significant economic effect [1].

Although there are numerous studies on the mechanism and kinetics of the thermal reactions of hydrocarbons they have had little impact on the practice of hydrocarbon pyrolysis, since the theories developed dealt mainly with individual hydrocarbons.

It is possible to develop new methods to improve the process of pyrolysis on the base of analysis of the mechanism occurring in the radical chain reactions.

\section{Discussion of the mechanism of pyrolysis}

Chain propagation reactions during pyrolysis are caused mainly by three particles - a hydrogen atom $\dot{H}$, methyl $\dot{C} H_{3}$ and ethyl $\dot{C}_{2} H_{5}$ radicals. The correlation of their influence on the process can be evaluated from the ratio of the concentrations of hydrogen, methane and ethane in the pyrolysis products. For example, the output ratio of hydrogen, methane and ethane was 1.2, 16 and $6 \mathrm{wt} . \%$, respectively, in the process of the pyrolysis of gasoline fractions, considering the molecular weight, the influence of hydrogen atoms, methyl and ethyl radicals on the substitution reactions was found to be 0.6:1.0:0.2. Thus, only a third of the circuits are propagated on the hydrogen atoms, and two-thirds - on the radicals, mainly methyl radicals.

Hydrogen atoms and methyl radicals differ significantly in the ratio of their reactivity in the substitution reactions according to various $\mathrm{C}-\mathrm{H}$ bonds. In the works of Korzun et al. [2, 4] and Korzun and Gagarina [3] the relative reactivity of hydrogen and methyl radicals was established and this is presented in Table 1.

On the base of data presented in Table 1 the probability of the formation of the primary radicals in the pyrolysis of n-heptane when being attacked by the methyl radical and hydrogen has been compared. In the case of the methyl radical reactions, the probability of the formation of the primary radicals with due consideration of the relative reactivity in its interaction with various $\mathrm{C}-\mathrm{H}$ bonds and the number of these bonds is equal to $\frac{6}{6+4.5 \cdot 2 \cdot 2+3 \cdot 2 \cdot 7}=\frac{6}{66}=0.091$. In the case of reactions with hydrogen atoms the probability of the formation of primary radicals is equal to $\frac{6}{16}=0.375$ and, therefore, more than four times higher than in the case of methyl radicals.

Decomposition of the primary radicals gives a much greater yield of ethylene than does the decomposition of secondary radicals which have different positions of free valence.

In the substitution reactions of the methyl radical with $\mathrm{n}$-heptane the radicals $\mathrm{CH}_{3} \mathrm{CH}_{2} \dot{\mathrm{C}} \mathrm{HCH}_{2} \mathrm{CH}_{2} \mathrm{CH}_{2} \mathrm{CH}_{3}$ and $\mathrm{CH}_{3} \mathrm{CH}_{2} \mathrm{CH}_{2} \dot{\mathrm{C}} \mathrm{HCH}_{2} \mathrm{CH}_{2} \mathrm{CH}_{3}$ occur with a probability of $\frac{6 \cdot 7}{66}=\frac{42}{66}$. The products of their decomposition are butane and pentene. In the case of the reactions with hydrogen the probability of the radicals 
formation is $\frac{6}{16}$, that is less by a factor of 1.7 than those for the methyl radicals. Thus, in the intermediate products resulting from the methyl radical chain propagation the concentration of $\alpha$-olefins $\mathrm{C}_{4+}$ is considerably higher than in the case of the chain propagation with the hydrogen atoms.

Table 1: The relative reactivity of $\dot{H}$ and $\dot{C} H_{3}$ in interaction with various $\mathrm{C}-\mathrm{H}$ bonds.

\begin{tabular}{|l|c|c|}
\hline Kind of reacting bond $\mathrm{C}-\mathrm{H}$ & $\begin{array}{c}\text { Reactions of } \\
\text { hydrogen atom }\end{array}$ & $\begin{array}{c}\text { Reactions of methyl } \\
\text { radical }\end{array}$ \\
\hline $\mathrm{RCH}_{2}-\mathrm{H}$ & $1^{*}$ & $1^{*}$ \\
\hline $\mathrm{CH}_{3} \mathrm{CH}-\mathrm{H}$ & 1 & 4.5 \\
\hline $\mathrm{R}_{1}>\mathrm{CH}-\mathrm{H}\left(\mathrm{R}_{1}, \mathrm{R}_{2}>\mathrm{CH}_{3}\right)$ & 1 & 7 \\
\hline $\mathrm{R}_{2}$ & 1 & 4.5 \\
\hline
\end{tabular}

*generally accepted.

Increase in the yield of ethylene when substituting aqueous vapour (inert diluent) for hydrogen is known [5-7]. The question of concern is the minimum amount of hydrogen required to produce the desired effect.

\section{Influence of hydrogen on the pyrolysis process}

The introduction of hydrogen into the feedstock under pyrolysis results in:

$$
\dot{\mathrm{C}} \mathrm{H}_{3}+\mathrm{H}_{2} \stackrel{k_{1}}{\longrightarrow} \mathrm{CH}_{4}+\dot{H} \text {. }
$$

The reaction with hydrogen (1) flows faster than in the following reaction:

$$
\dot{\mathrm{C}} \mathrm{H}_{3}+\mathrm{RH} \stackrel{k_{2}}{\longrightarrow} \mathrm{CH}_{4}+\dot{\mathrm{R}}
$$

as the rate constant for the reaction (1), $k_{l}$, is significantly higher than the rate constant for the reaction (2), $k_{2}[8]$.

In the pyrolysis of gasoline with molecular weight 98 and hydrogen supply in the amount of 2 wt.\% the mole ratio of the hydrogen and hydrocarbons concentration is an equal one. Therefore, methyl radicals are replaced by hydrogen atoms to a considerable degree. Thus, as in reaction (3):

$$
\dot{H}+\mathrm{RH} \stackrel{k_{3}}{\longrightarrow} \mathrm{H}_{2}+\mathrm{R}
$$

$k_{3}$ is much higher than $k_{2}$, hydrogen plays the role of the homogeneous catalyst of the process.

At the given temperature of pyrolysis the dependence of the ethylene yield on the reaction time goes through a maximum owing to the higher ethylene 
consumption rate as compared with the rate of its formation. The reaction which is the most probable reason for the ethylene consumption is (4a):

$$
\begin{gathered}
\dot{R}+\mathrm{C}_{2} \mathrm{H}_{4} \longrightarrow \dot{C}_{2} \mathrm{H}_{3}+\mathrm{RH}, \\
\dot{\mathrm{C}}_{2} \mathrm{H}_{3}+\mathrm{C}_{2} \mathrm{H}_{4} \stackrel{k_{4}}{\longrightarrow} \mathrm{C}_{4} \mathrm{H}_{7} \longrightarrow \mathrm{C}_{4} \mathrm{H}_{6}+\text { condensation products. }
\end{gathered}
$$

In the presence of hydrogen as a competing reaction to (4a) the following reaction appears:

$$
\dot{C}_{2} H_{3}+H_{2} \stackrel{k_{5}}{\longrightarrow} C_{2} H_{4}+\dot{H} .
$$

The rate constant for the reaction (5), $k_{5}$, is more an order of magnitude than the rate constant for the reaction $(4 \mathrm{a}), k_{4}$.

At the ethylene yield of $28 \mathrm{wt} . \%$ and hydrogen concentration of $2 \mathrm{wt} . \%$ the molar ratio of concentration $\frac{\left[\mathrm{H}_{2}\right]}{\left[\mathrm{C}_{2} \mathrm{H}_{4}\right]}$ is equal to one.

In fact, the required amount of hydrogen must be less than $2 \mathrm{wt} . \%$ taking into account the hydrogen newly-produced in the pyrolysis process.

Thus, the introduction of hydrogen increases the selectivity of ethylene formation and, with an amount of approximately 2 wt.\%, inhibits the consumption of ethylene. It should also be noted that increasing the concentration of hydrogen significantly reduces the rate of pyrolytic carbonization on the walls of the reaction coil [5]. The pyrolytic carbon extraction rate reduces in the presence of $2 \mathrm{wt} \%$ of hydrogen by a factor of almost two, significantly increasing the overhaul life.

It should be noted that the introduction of $2 \mathrm{wt} . \%$ of hydrogen reduces the consumption of aqueous vapour, which is used as a diluent of the hydrocarbon feedstock, by 18 wt. $\%$.

In the process of the pyrolysis of gasoline fraction at $85-150^{\circ} \mathrm{C}$ by means of the simulation laboratory apparatus following the introduction of $2 \mathrm{wt} . \%$ of hydrogen the yield of ethylene increased by $6.0-35.8$ rel.\% consistently with the reaction time while reducing the yield of liquid products by $11.9-48.9$ rel.\% (Table 2). It follows from the data presented in Table 2 that at the pyrolysis time of more than $0.5-0.7 \mathrm{sec}$ an introduction of $2 \mathrm{wt} . \%$ of hydrogen inhibits the reaction of ethylene consumption, resulting in a decrease in its yield and also prevent the formation of condensation products.

\section{Conclusion}

Methyl radicals and hydrogen atoms, which are the chain carrier radicals in the pyrolysis of hydrocarbons, strongly differ in their selectivity in the substitution reactions on the $\mathrm{C}-\mathrm{H}$ bonds. Hydrogen atoms are much less selective than methyl radicals, whereby, the ratio $[\mathrm{H}]:\left[\mathrm{CH}_{3}\right]$ in the reaction mixture strongly affects the final product of pyrolysis. By increasing this ratio there is a greater probability of the formation of primary alkyls and, as a result, the ethylene yield increases. 
Table 2: Influence of hydrogen on the results of the pyrolysis of gasoline fraction $85-150^{\circ} \mathrm{C}\left(\mathrm{T}=810^{\circ} \mathrm{C}\right.$, the total pressure is equal to atmospheric pressure).

\begin{tabular}{|c|c|c|c|}
\hline \multirow[b]{2}{*}{$\begin{array}{l}\text { Reaction time, } \\
\text { sec }\end{array}$} & \multirow[b]{2}{*}{ Reaction products } & \multicolumn{2}{|c|}{ Mass yield, $\%$} \\
\hline & & $\begin{array}{l}\text { Without } \\
\text { hydrogen }\end{array}$ & $\begin{array}{l}\text { At introduction } \\
\text { of } 2 \mathrm{wt} . \% \text { of } \\
\text { hydrogen }\end{array}$ \\
\hline \multirow{5}{*}{0.15} & $\mathrm{CH}_{4}$ & 11.9 & 7.5 \\
\hline & $\mathrm{C}_{2} \mathrm{H}_{4}$ & 26.3 & 30.0 \\
\hline & $\mathrm{C}_{3} \mathrm{H}_{6}$ & 17.5 & 20.6 \\
\hline & Hydrocarbons $\mathrm{C}_{4}$ & 11.9 & 3.8 \\
\hline & Liquid products $\mathrm{C}_{5+}$ & 34.4 & 20.0 \\
\hline \multirow{5}{*}{0.50} & $\mathrm{CH}_{4}$ & 13.1 & 8.1 \\
\hline & $\mathrm{C}_{2} \mathrm{H}_{4}$ & 31.9 & 33.8 \\
\hline & $\mathrm{C}_{3} \mathrm{H}_{6}$ & 19.4 & 16.3 \\
\hline & Hydrocarbons $\mathrm{C}_{4}$ & 6.3 & 3.8 \\
\hline & Liquid products $\mathrm{C}_{5+}$ & 24.4 & 22.5 \\
\hline \multirow{5}{*}{0.70} & $\mathrm{CH}_{4}$ & 14.4 & 9.4 \\
\hline & $\mathrm{C}_{2} \mathrm{H}_{4}$ & 31.3 & 35.0 \\
\hline & $\mathrm{C}_{3} \mathrm{H}_{6}$ & 18.8 & 14.4 \\
\hline & Hydrocarbons $\mathrm{C}_{4}$ & 5.6 & 3.8 \\
\hline & Liquid products $\mathrm{C}_{5+}$ & 23.8 & 22.5 \\
\hline \multirow{5}{*}{0.90} & $\mathrm{CH}_{4}$ & 15.6 & 10.6 \\
\hline & $\mathrm{C}_{2} \mathrm{H}_{4}$ & 30.6 & 35.6 \\
\hline & $\mathrm{C}_{3} \mathrm{H}_{6}$ & 17.5 & 11.3 \\
\hline & Hydrocarbons $\mathrm{C}_{4}$ & 6.3 & 3.8 \\
\hline & Liquid products $\mathrm{C}_{5+}$ & 25.6 & 20.0 \\
\hline \multirow{5}{*}{1.30} & $\mathrm{CH}_{4}$ & 18.1 & 12.5 \\
\hline & $\mathrm{C}_{2} \mathrm{H}_{4}$ & 26.3 & 35.7 \\
\hline & $\mathrm{C}_{3} \mathrm{H}_{6}$ & 12.5 & 8.8 \\
\hline & Hydrocarbons $\mathrm{C}_{4}$ & 6.9 & 3.8 \\
\hline & Liquid products $\mathrm{C}_{5+}$ & 33.8 & 16.3 \\
\hline
\end{tabular}

Simultaneously, the hydrogen inhibits the reaction, which reduces the yield of ethylene, and reduces the formation of pyro-carbon. The critical amount of hydrogen for obtaining the desired effect of improving the selectivity for ethylene is approximately $2 \mathrm{wt} . \%$.

\section{References}

[1] Wang, X.Q., Xie, C.G., Li, Z.T. \& Zhu, G.Q. Catalytic processes for light olefin production (Chapter 5). Practical Advances in Petroleum Processing, eds. C.S. Hsu \& P.R. Robinson, Springer Science - Business Media, Inc.: New York, Vol. 1, pp. 149-168, 2006. 
[2] Korzun, N.V., Gagarina, L.V. \& Barabash, V.B., Relative reactivity of C-H bonds in the process of hydrocarbon pyrolysis. Journal of Physical Chemistry, 59(8), pp. 1888-1893, 1985.

[3] Korzun, N.V. \& Gagarina, L.V., Relative reactivity of various C-H hydrocarbons bonds. Journal of Petroleum Chemistry, 25(4), pp. 514-523, 1985.

[4] Korzun, N.V., Gagarina, L.V., Barabash, V.B. \& Magaril, R.Z., Pyrolysis behavior of hydrocarbon mixtures. Journal of Physical Chemistry, 59(8), pp. 1894-1898, 1985.

[5] Magaril, R.Z., Theoretical foundations of chemical refining processes, [in Russian], KDU: Moscow, 2010.

[6] Korzun, N.V. \& Magaril, R.Z., Thermal processes of refining, [in Russian], KDU: Moscow, 2008.

[7] Demidenko, M., Magaril, R. \& Magaril, E. Aqueous vapour substitution for hydrogen in the process of pyrolysis. WIT Transactions on Ecology and the Environment, 190, WIT Press: UK, pp. 855-865, 2014.

[8] Kondratyev, V.N., Kinetic constants of gas-phase reactions. Reference book, [in Russian], Nauka: Moscow, 1970. 